
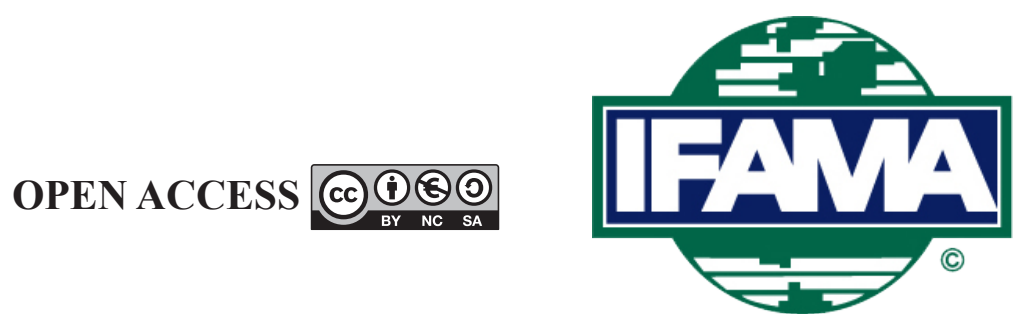

International Food and Agribusiness Management Review

Volume 24, Issue 2, 2021; DOI: 10.22434/IFAMR2019.0195

Received: 20 November 2019 / Accepted: 29 January 2020

Special track: European agrifood business in transition towards social responsibility

\title{
Sustainable demand-supply chain: an innovative approach for improving sustainability in agrifood chains \\ REVIEW ARTICLE
}

\author{
Maryline Filippi ${ }^{\circledR a, b}$ and Alain Chapdaniel ${ }^{\mathrm{c}}$ \\ ${ }^{a}$ Professor, Bordeaux Sciences Agro, University of Bordeaux, \\ 1 avenue du Général de Gaulle, 33175 Gradignan, France \\ ${ }^{b}$ Associated Researcher, UMR SAD-APT, University of Paris Saclay, \\ 16 rue Claude Bernard, 75005 Paris, France
}

${ }^{c}$ Director, SDSC Chair, University of Paris-Saclay, 16 rue Claude Bernard, 75005 Paris, France

\begin{abstract}
Increasing price volatility and the decrease in both raw material prices and farmers' incomes, all underline the depths of the French agricultural crisis. How should the relationships within agrifood supply chains be envisaged in order to obtain greater sustainability combined with better added-value distribution? This article introduces a new approach for supply chain organization and management: the sustainable demand-supply chain. The paper mobilizes both management, organization and innovation literatures, together with a case study based on data from farmers, cooperatives and distributors in the pork sector. The originality of the paper lies in its modelization of sustainable demand-supply chains. The results show that new relationships need to be implemented between all stakeholders, including consumers - both to share information and to define their new added-value distribution. The results identify the key points of this new supply chain coordination and indicate policy recommendations for organizational innovations.
\end{abstract}

Keywords: contract, sustainable supply chain, agrifood, organizational innovation, supply chain management JEL code: L2, O13, Q13

(ํ) Corresponding author: maryline.filippi@agroparistech.fr 


\section{Introduction}

Increasing price volatility and the decrease in both raw material prices and farmers' incomes, all underline the depths of the French agricultural crisis in meat, cereals or dairy products. These sectorial crises reveal the weakness of French agriculture competitiveness and the lack of coordination in the agrifood supply chains. How should the relationships within those supply chains be envisaged to obtain greater sustainability together with better added-value distribution?

This article introduces a new approach for supply chain organization and management: the sustainable demand-supply chain (SDSC). SDSC analyzes flows between stakeholders, especially farmers, processors, distributors and consumers in order to ensure better added-value creation and distribution for all. The objective is to discuss the conceptualization of SDSC within the innovation system approach, including what concerns its multilevel dimensions. How can SDSC be conceptualized, measured and developed?

The SDSC approach mobilizes two main concepts, extended demand and creating/sharing added value, which together require shared supply chain governance. SDSC is an innovative approach using two concepts: (1) extended demand, comprising demand expressed by customers and either stakeholders; and (2) the demandsupply chain (DSC), a co-creative group of stakeholders which creates and shares added-value. The SDSC approach introduces new form of governance in order to ensure sustainable commitment. This avoids conflicts and the destruction of added value by stiff competition. SDSC, like supply chain management, improves coordination between stakeholders, using both information technology and indicators to share value and to integrate the new forms of contract. In this perspective we have, on the one hand, technical problems and, on the other, relationship problems. In the present contribution, we focus on the second dimension.

The paper mobilizes both management, organization and innovation literatures (Chassagnon, 2011; Elzen et al., 2004; Ketchen and Hult, 2007; Lazzarini et al., 2011; Wieczorek and Hekkert, 2012) in order to better understand how to analyze and measure the added value created by SDSC. The case study used to illustrate the paper employs data from farmers, cooperatives and distributors in the pork sector. This sector is particularly interesting because, even if pig farmers perform well technically, they are losing their market shares in both national and international markets. The case study details both the data collection (definition and type of data), and the data analysis (qualification of data, triggers, individual and global performance). In order to model the flow between stakeholders, new collaborative traceability tools are needed (based on the new EPCIS standard of GS1 (GS1, Paris, France)) and simulation-optimization.

The originality of the paper lies in using SDSC to propose a modelization of sustainable demand-supply chains. The results show that new relationships need to be implemented between all stakeholders - both to share information and to define their new added-value distribution. Modelization is needed in order to show how flows of products move, and how selling prices reveal the added-value allocation. The results identify the key points of this new supply chain coordination and suggest organizational innovations. The paper concludes with the need for public policy makers to authorize the use of new contractual tools.

\section{Context and theoretical background}

Agrifood sectors are often defined through their production components, but without including the distributors. They have, of course, strong impacts on production, especially via distributor brand product specifications, particularly when these incorporate specific environmental or social objectives (Berger et al., 2015). Supply Chains management or filière are renewal concepts due to societal pressure to face sustainability versus market competition. 


\subsection{Agrifood supply chains for sustainability}

The concept of supply chain management, whether between production and distribution or between production actors, is not very developed in many agrifood sectors. When the chain is managed, this is almost always done independently of demand management, as is also often the case in non-agrifood sectors (Kusi-Sarpong et al., 2019). It should be noted, however, that as the different forms of leverage to create value are linked; the supply and demand changes need to be jointly managed. This is done at actor level, through sales and operation planning, even though this process is not yet widely implemented.

Usually each actor tries to maximize profits on an individual basis, however illusory that approach may prove to be. But it is even more absurd to try to optimize environmental or social results at a single actor level. We often see individual actors working on different topics without any attempts at coordination. Inevitably, the results are too atomized to be valorized for consumers or other stakeholders and sometimes, even, the results cancel out each other.

One consequence of this is that actors share very little information, restricted for the most part to ordering and invoicing information. Even those traceability information systems that are put in place are very often basic, in house-solutions, merely set up to exchange data between actors.

Another characteristic of the agrifood sector concerns the metric used in strategic environmental topics. Usually, individual actors establish their own specific Life Cycle Assessment (LCA) on different products. As these LCAs are rarely shared between actors, and are built on different domain and different leading data, it is hard to define a common strategy and common criteria focused on environmental aspects. A similar problem exists for defining social criteria. Another difficulty in promoting work carried out on environmental aspects is the LCA product approach. The actions of certain environmental actors are made independently of their products. These actions could be discussed between actors, constituting part of a common environmental strategy, and thereby creating value (Gereffi et al., 2005). One final characteristic is that currently it is the agrifood sector organizations themselves which often promote price volatility and speculations. That makes it hard to create a circular economy or to develop short supply chains (Marsden et al., 2000).

\subsection{Theoretical proposals to take supply chains problems into account}

The literature in economics, management, organization and logistics focuses on different aspects of supply chains. Various authors have analyzed how firms coordinate and build an supply chain as an organizational and productive entity. For these scholars, the main theoretical economic contributions are:

- The theory of the nexus of explicit contracts: the nature of the firm is based on the organization of a bundle of various different contractual arrangements (Alchian and Demsetz, 1972; Fama, 1980; Jensen and Meckling, 1976). This nexus of explicit contracts leads scholars to suggest ways of reconciling opposing interests.

- The theory of property rights: the firm as a collection of non-human assets, which argues that firms arise when market contractual relationships fail (Grossman and Hart, 1986; Hart, 1995; Hart and Moore, 1990), with organization relationships being analyzed via a property rights reading.

- Transaction cost economics: the firm as a governance structure of contracts (Coase, 1937; Williamson, $1975,1985)$. Using the transaction cost point of view, the integration into supply chain is considered as a way to reduce costs and opportunistic behaviors.

Consequently, coordination between stakeholders needs to be supported by technical tools, contracts and organizational arrangements. Together with management and organization literature, supply chain mobilizes supply chain analysis (vertically organized, sequential transactions) and network analysis (horizontal bonds between companies). Referring to the literature, Nasueilli et al. (2015:3) argue that supply chains should be treated as complex adaptive systems, and they propose to exploit some of the concepts, tools and techniques used in the study of complex adaptive systems to characterize and model supply-chain networks. Lazzarini 
et al. (2001) suggest that supply chain analysis should study the vertically organized sequential transactions, which represent the successive stages of creating value along the supply chain. However, network analysis is not particularly concerned with vertically organized links, but rather with horizontal bonds between companies in particular industries or groups (Surana et al., 2005). That is why Lazzarini et al. (2001) introduce the concept of netchain analysis:

'a netchain is a set of networks comprised of horizontal ties between firms within a particular industry or group, which are sequentially arranged based on vertical ties between firms in different layers. Netchain analysis interprets supply chain and network perspectives on inter-organizational collaboration with particular emphasis on the value creating and coordination mechanism sources. The recognition and accounting of these simultaneous interdependencies is crucial for a more advanced understanding of complex inter-organizational relations.'

A netchain is a network formed by a set of networks composed of horizontal bonds between firms within a particular segment and arranged sequentially according to vertical ties between firms in different layers, or in different segments. Netchain analysis draws an explicit distinction between horizontal bonds (in the same layer) and vertical links (in different layers), mapping out how agents in each layer are related to other agents and to agents in the other layers (Ketchen and Hult, 2007). The question of the power in supply chain management (Cox et al., 2001; Ireland and Webb, 2007; Reimann et al., 2017) reinforces the perspectives for renewing complex relationships in food chains. Supply chains are becoming increasingly complex (Gereffi et al., 2005; Rastoin and Ghersi, 2010), and intensified competition in the end markets has started to create a situation where cooperation requirements between companies are increasing, and old mechanistic operations management solutions are becoming obsolete (Gold and Schleper, 2017; Ketchen and Hult, 2007). Although a network approach to supply has been extensively acknowledged in supply chain literature, the supply chain concept focuses on supply and considers the effects of demand to be an exogenous factor (Rezaee et al., 2015). This is why we need to create a new approach in order to work more efficiently and create more value, in order to satisfy the economic environmental and social expectations of the consumer and all stakeholders (Nieuwenhuis et al., 2019), combined with a fair distribution between everybody. This is the main objective of the SDSC approach.

\section{SDSC approach: an innovative mix of sustainability and new governance}

This part describes the SDSC approach and its associated tools, clearly pointing out their innovative aspects.

\subsection{SDSC approach perception}

There are two major considerations in the SDSC approach. One is to place sustainable development at the very heart of strategy. The second, resolutely innovative in nature, is to promote joint management of the demand and supply chain (both at actor and inter-organizational level). The SDSC approach is based on two concepts: specified extended demand and DSC. This section explains these two innovative concepts.

\section{- A need for coherence in sustainability strategy at the sector level}

The consideration of environmental and social objectives requires coherence through the whole chain (Gold and Schleper, 2017). In consequence, it also encourages and facilitates collaboration among actors. For example, a life cycle analysis is made at the inter-organization level: actors must collaborate to collect and aggregate data. These data must be coherent, and actors must define coherent improvement actions. The choice of stakeholders, that has to be taken into account in the strategy, has also to be discussed among the actors (this discussion is part of the SDSC approach and is described below, together with the specification of extended demand). Another positive advantage is that such essential environmental and social discussions between actors also incite them to re-think their individual economic optimization, allowing them to discover a more lucrative organization at a global level. 


\section{- Promotion for joint management of the demand and the supply chain}

This joint management of the demand and supply chain takes place at both intra-organizational and interorganizational level. It can be applied to different areas. For example, in pricing and promotional campaign management: sudden changes in prices (up or down) have consequences on sales levels and must be decided in terms of production and logistic capacities. This joint management approach avoids spending on advertising when there are no products to sell, or in case of waste due to large returns of unsold products. This joint management begins with sharing forecasts in order to establish coherence within the whole chain, (avoiding the whip effect, for example, and also easing the definition of common scenarios for demand variations). It can also help in organizing the donation of short best-before date food to charity, free of charge. The joint management could also consist in finding value from co-products (with new profits and a decrease in waste), or by designing promotional packaging to ease the promotion and reduce workers' fatigue (for example, ready-to-sell displays), or classical supply chain optimization by transport pooling (full trucks, less $\mathrm{CO}_{2}$ ).

\subsection{The main concepts of the SDSC approach}

The need for coherence between actors on environmental and social aspects and the joint management of supply chain and demand imply deep changes in the sector organization and governance. To better understand and implement the SDSC approach, two operational concepts has been developed in the next section: the 'specified extended demand' and the 'demand-supply chain'. The SDSC acceptance is also eased by specific tools that develop DSC confidence; these are detailed in the last part.

\section{- The specified extended demand}

The main idea is to take in consideration not only consumers' expectations, but also those of stakeholders. These expectations concern specification of the product and its associated services; the price, of course, but also environmental and social aspects. This expectations analysis is split into two steps: first, the consumer demand is analyzed, and secondly the expectations of the supply chain stakeholders. A choice is subsequently made regarding the various consumer and stakeholder demands to be kept and specified. The specification can be made by one or several actors.

In the SDSC approach, 'consumer demand' has various components: the product description (including services). Additional requests may arise regarding packaging, use, end of life, information on production and supply chain characteristics, actors' remunerations. This consumer demand can be explicit or implicit. And it is sometimes hard to pin down exactly. The specification of consumer demand is a strategic process (made by an actor or group of actors) according to the actors' possibilities and their strong desire to innovate. This specification consists mainly in choosing demand components which will be satisfied or partially satisfied (or even refused), subsequently followed by integrating additions or modification based on actors' innovations. All that has then to be translated into functional specifications and a set of sustainable development criteria (economic, social, environmental); these criteria are quantified, and the measurement and calculation methodology are given.

'Associated demands' describe the demands of other stakeholders' in connection with consumer demand. These demands concern the main supply chain actors bringing the product or service to the consumer, but also joint supply chains actors (for co-products, reverse supply chain, ONG for food distribution). Associated demands also take into account one or more other stakeholders (state, local authorities, NGOs, associations, labor unions, sector representatives).

Global 'specified demand' is based on both consumer demands and these associated demands. The overall process is still the same: choice of demand components to be satisfied or partially satisfied (or even refused), additions or modification based on actors' innovations, followed by translating all of that into functional specifications and a set of sustainable development criteria (economic, social, environmental); again, these criteria are quantified, and have to be coherent with the previous ones regarding consumer demand. 


\section{- Demand-supply chain}

Extended demand is specified by a set of actors who share the same target vision. We propose to call this co-creative group of stakeholders the DSC. This DSC does not usually include all the supply chain actors but only those who decide to work together and agree on the specified extended demand to be satisfied. The DSC actors can be certain members of the main supply chain, but also those handling co-products, waste, energy, as well as others who, each in their own way, contribute to a responding to the specified extended demand; such as actors managing environmental or social information.

The question (which is also a strategic one) is how to identify those actors who will constitute the DSC. This could be done in different ways. Sometimes there is a particularly innovative actor in a sector, who first defines the specified extended demand, and then looks for partners to set up the DSC. Sometimes a 'DSC' is already in place, due to historical connections, and the extended demand is done all together; the DSC may then be extended at a later stage, with actors attracted by the DSC performance.

Once the DSC is constituted and the extended demand specified, the question then arises: how should the DSC be organized and managed in order to satisfy the specified extended demand? This general question can be split into three. Firstly, what are the levers of action to create value and how can they all be operated together? Secondly, what information systems and tools are necessary to support DSC operations and provide information to consumers and stakeholders? And lastly, how should risk, profit and loss, as well investment aspects, be shared among DSC members via the corresponding multilateral contracts?

Figure 1 give an example of a DSC: the French pork sector application, which is described in Section 4. This DSC is constituted of the same actors (but necessarily not all of them) of different supply chains and different organizations (for example, Terrena, an agricultural cooperative and Système U, a distribution cooperative). The main supply chain is composed of an animal food plant, breeders, a cutting plant, a transformation plant, distribution platforms, stores and customers. Closed loops exist, for example: agricultural producer à soymeal for breeders à manure used to fertilize the fields of agricultural producers.

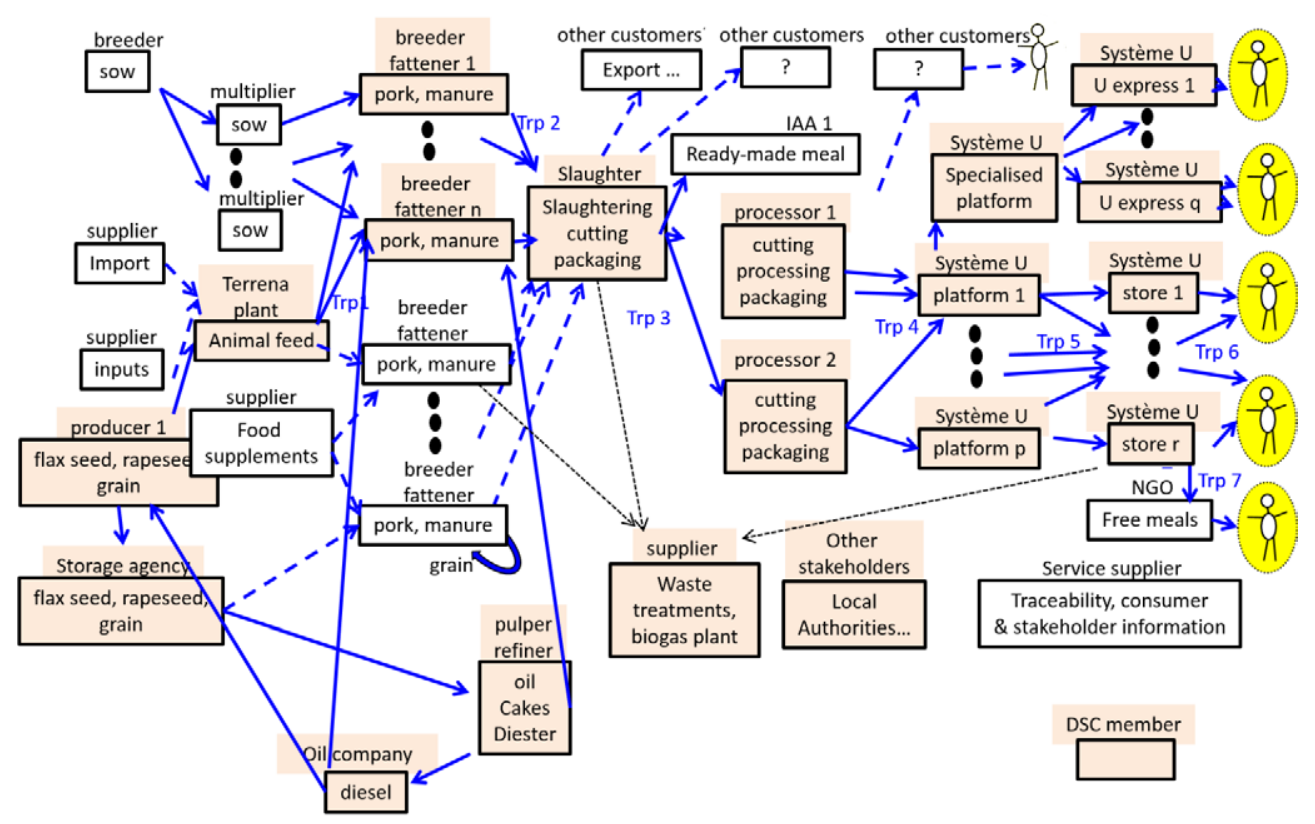

Figure 1. Example of a demand-supply chain: the French pork application. 
Other supply chains focus on the valuation of co-products or could have social objectives, such as the distribution of unsold articles through NGOs. The goal of the SDSC approach is not to optimize the main supply chain, but to satisfy a specified extended demand as defined by a DS. This means optimizing the main supply chain, but also the other connected supply chains on which the DSC members want to interact, not only from the economic point of view but also in terms of the sustainable development criteria defined by the DSC.

\subsection{Useful tools for confidence within demand-supply chain}

The final utility of DSC tools is to help in creating value and sharing it fairly between customers and other stakeholders. But their most important role is to create confidence within the DSC, and to enable people to work together in a different way, thereby creating a new sector governance. So, the way of co-creating these tools is even more important than their quality per se, especially in the early days of SDSC approach implementation. For example, the most useful DSC tool is one helping decision-making by easing the joint management of the supply chain and demand. This could be built up from scratch but there is a more innovative way to do it. And this way also helps management change within the sector by co-creating a first level of confidence. This tool could be derived from a traceability tool.

The idea is to first ask actors to implement a new inter-operable traceability tool based on the new GS1 standard (EPCIS). This implementation is often a first opportunity to accept to share electronic data between actors' information systems. As these exchanged data are not conflictual, the traceability system could be operational rather quickly. This first system increases the confidence between actors and could also create value for each and every one of them. Trustworthy and rapid information on ingredient origins and elaboration processes could be valuable for customers or local authorities. This traceability tool could also be upgraded in ways not typically associated with the SDSC approach.

Besides traceability data, other sustainable data, such as economic, social and environmental data, could be recorded in the same EPCIS format. So, the whole DSC now has a shared database with traceability data, and economic, social and environmental additional data. Specific tools can be derived from this database, as described in Figure 2:

- Calculation modules for sustainable criteria: fossil fuel energy, $\mathrm{CO}_{2}$, local employment, work fatigability.

- Simulation tools for jointly optimizing the supply chain and demand by operating levers on production, logistic and demand (with calculations on economic, environmental and social impacts based on previous calculation modules).

- Performance measurement tools at DSC and actor level on economic, environmental and social dimensions. This tool proposes a distribution value between DSC actors (including the customer) and forms the basis for new forms of contractualization within the DSC.

- Supply information tools for availability of information for customers and other stakeholders, but also for added-value information for other customers (as done by Microsoft, Google, Amazon for their captured data).

Of course, all these tools have access filters, and not all the data are accessible by everybody. 


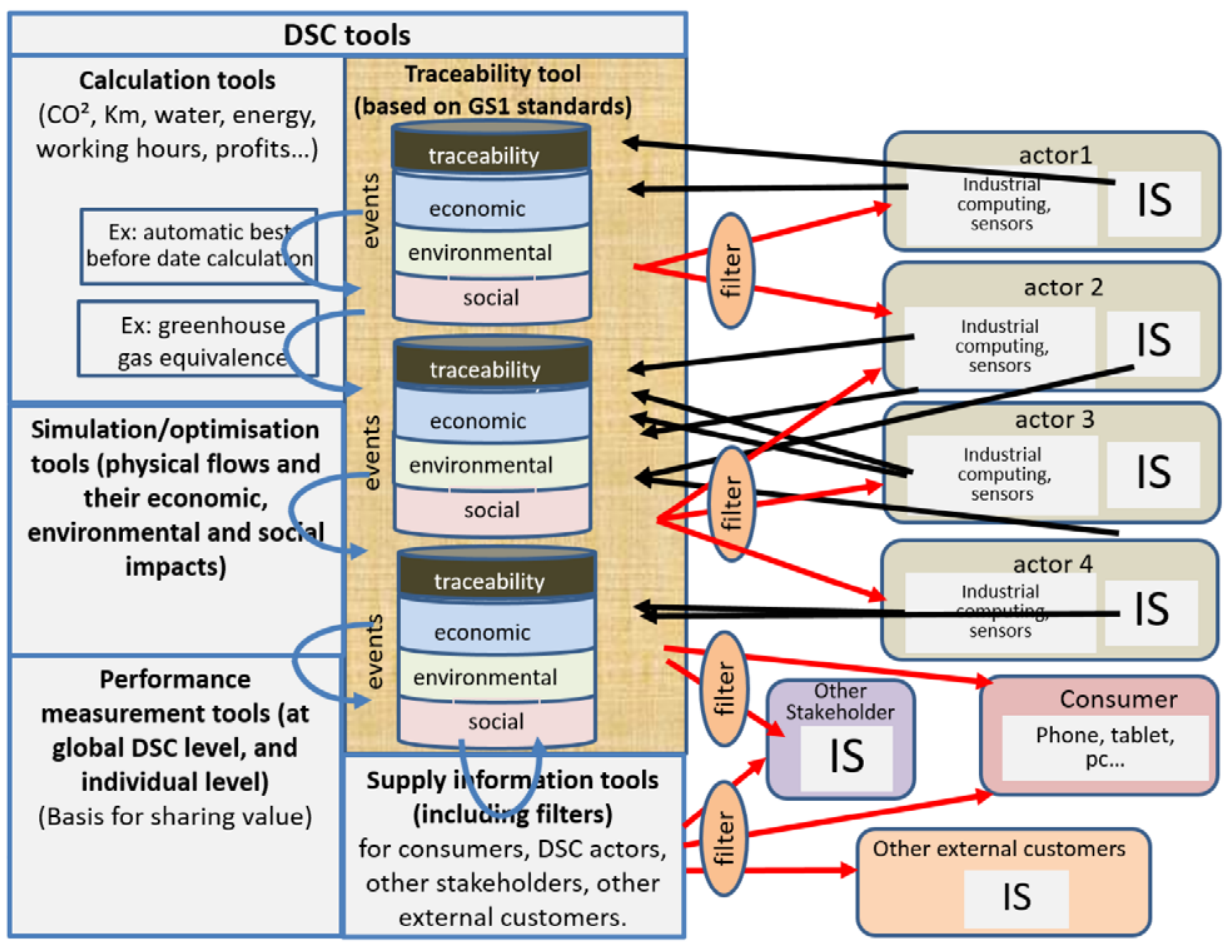

Figure 2. Demand-supply chain tools.

\section{Application to French pork sector}

This part describes a case study on an SDSC approach application to the French pork sector called Pork 'nouvelle agriculture ${ }^{\circledR} U^{\circledR}$,

\subsection{Introduction Pork' 'nouvelle agriculture ${ }^{\circledR} U^{\circledR}$,}

Nouvelle agriculture ${ }^{\circledR}$ and $\mathrm{U}^{\circledR}$ are two brands. The former belongs to the French cooperative 'Terrena', the latter to the French distributor 'Système U'. The Pork 'nouvelle agriculture ${ }^{\circledR} \mathrm{U}^{\circledR}$ ' is described on Terrena website ${ }^{1}$ :

'Terrena and the Système U supermarket chain have signed a partnership involving the production and marketing of La Nouvelle Agriculture ${ }^{\circledR}$ pork. Système U will market fresh products coming from 50,000 pigs fed on Bleu-Blanc-Coeur ${ }^{2}$ (Omega 3) feed, without GMO and of French origin. The contracts have been signed for a three-year, renewable period. The pig producers agree to set-up a plan reducing the use of antibiotics. 24 product references will be marketed.'

This partnership is innovative in itself. Both brands are clearly shown on the punnets. The product specifications have been made together (the two actors have thus discussed product characteristics, but also the environmental and social aspects they want to promote. Terrena and Système U, both SDSC chair sponsors, wanted to experiment the SDSC approach on their pork partnership. The different project phases are described in the next paragraph.

\footnotetext{
${ }^{1} \mathrm{http} / /$ www.terrena.fr/en/la-nouvelle-agriculture-products

2 Bleu-blanc cœur. Available at: http://www.bleu-blanc-coeur.org (in French)
} 


\subsection{Pork SDSC approach agenda and data}

- The first phase consisted in mutual discovery for all actors. They exchanged their way of doing business and their concerns about environmental and social job contexts. They also detailed their strategies and their associated improvement plans. As this phase was not particularly innovative, it has not detailed in this paper (a classical first phase for a project: team building, brainstorming, for example the Lego serious play ${ }^{\circledR}$ was used).

- The second phase was the 'extended demand specifications', which meant the analyses of consumer and other stakeholder expectations, the actors' choices on what to take into consideration and the innovations they wanted to include in their response. The next paragraph explains the pork SDSC approach objectives, which the actors finally defined during this strategic phase.

- The third one was data analysis throughout the whole chain in order to find levers to create value. This would give the basis for modeling interactions within the DSC.

- During the fourth phase, actors chose the levers they wanted to use and how they could use them in a coordinated and efficient manner. A dedicated tool prototype was made at this time.

- The fifth phase is still in progress. The new combined management of demand and supply chain is being tested and the benefits measured.

\section{- Pork SDSC approach objectives (phase 2)}

The main objective is to create added value and redistribute it fairly between all stakeholders (consumers, Terrena, Système U, local authorities, French state, NGOs). Besides the product specification, the main extended demand criteria specified in the second phase of SDSC approach are the following. The most important one is economic: to guarantee the DSC actors' sustainability (in particular, that of breeders); and to increase the global margin of all DSC actors (farmers, breeders, slaughterhouse, transformation units, animal feed plant, carriers, Système U platforms and stores). All of this is subject to one constant constraint: to keep consumer sale prices at market levels.

The second objective is to decrease waste (in particular material waste, down-gradings, etc.) The third one is to promote the 'local' aspect (especially local employment). The last two objectives are to increase product quality by a better production and supply chain organization (focused on product specifications regarding non-GMOs, antibiotics, Bleu-Blanc Coeur specification) and to increase animal welfare (breeding conditions, transport, slaughterhouse stress, etc.).

Of course, the general objectives of a SDSC approach are also mandatory. The first one is to have a transparent model, accepted by all DSC members. This model eases the supply chain design but also constitutes the kernel of a simulation tool (economic, but also environmental and social). The simulation has different horizons: six months, one month and daily for the supply chain and demand management.

The model can also automatically calculate transfer prices for DSC actors (by, for example, using revisable fixed prices in order to fight against price volatility and speculation). The final general objective for this model is to serve as the basis for a business agreement. In order to achieve all these objectives, there is a need to establish new governance between Terrena and Système U, and also inside the two organizations.

\section{- Pork supply chain and demand data analysis (phase 3)}

Large data analysis has been conducted. The aim was to identify the more pertinent levers to create value, particularly those which have consequences in other places along the chain. These interactions were captured in a representative model succinctly described in the next paragraph.

Out of all the millions of analyzed data (daily level), the most useful category was that which gave details for each breeding unit: pig births (and accidental deaths), pig shipment to slaughterhouse (number of hogs, 
morphologic and quality characteristics, transfer prices), and production costs (mainly animal feed costs). Slaughterhouse data has also been analyzed: entries, production lot details (number and weight of pieces by category, with their associated quality characteristics) and stock level by category. The transformation process has been also examined using transformation unit data: entries, production details (mainly punnets) quantity and weight, and stock levels by category (inputs and outputs).

For System U platform and stores (details at store level): ordered quantity and weight by article, sales by article, transfer and selling prices, promotion campaigns and stock level by category (platform and stores). Consumer's complaints were also available.

Thanks to all this data, the order process throughout the entire chain could be analyzed and the flow organization (material and informational flow). It should be noted that, very often, information is only shared between two actors, with nobody having the global flow vision. Another example regards the yearly forecast made and discussed between Terrena and Système U, but without any other forecast being exchanged during the year, except the figures for promotion campaigns.

\subsection{Pork SDSC model and results}

\section{- A simple SDSC model}

The descriptive model has been voluntarily simplified in order to be easily understood, and adopted by all the actors, and also to have fairly simple easy-to-use derive tools. The main data and explanatory variables bound by equations are the supply chain demand data. The main supply chain data are: (1) birth and death in breeding unit; (2) number of available pigs to send to slaughterhouse per breeding unit; (3) number of available meat pieces produced at slaughterhouse; (4) available final products for sales; (5) stocks all along the chain. The main demand data are sales forecasts (including promotion), selling prices, quantity and price promotions. The model can calculate the downgrading forecast at slaughterhouse, transformation unit and stores.

Based on this model, a simulation tool has been developed, which calculates the adequacy between forecast demand and supply, and the resultant associated downgrading. The main adjustment levers are 'supply' or 'demand' ones. Supply chain levers are the number of births, advance or delay in sending hogs to slaughterhouse. The main demand levers are: (1) store assortments; (2) selling prices; (3) quantities; and (4) prices for promotion campaigns.

\section{- Three first results of pork SDSC approach}

Three benefits brought by the SDSC approach can already be seen. The first one is a change in the order process throughout the chain: it now flows more harmoniously and has virtuous consequences on production organization (at slaughterhouse and transformation units). The second benefit is a better organization for animal collection tours for the slaughterhouse, which improves animal welfare, meat quality and the slaughterhouse organization (animal rest durations). The third one is better adequacy between supply and demand and, consequently, a decrease in downgrading both in slaughterhouse and transformation units (this result is a combination of more flexible production and more judicious promotion campaigns).

The next expected results concern a new way of contractualization: fixed prices (with revision mechanisms) for all transfer prices within the DSC. The transfer prices are then calculated by the agreed model. Another area of expected improvement is the integration of new actors in the DSC in order to have a better material balance. This means the DSC, with different actors able to buy and sell all parts of a pig. Système U, for example, does not currently sell all pig parts in its stores. 


\section{Discussion}

As an innovative approach, SDSC combines various characteristics, such as a range of different actors, extended demand and a need for a new SDC governance. Future points to be discussed mean that: (1) in order to build confidence between actors, the contractual tools have to change. The two-party contract must be replaced by multipartite agreements; this particular point is described in section 5.1 ; (2) the competition rules have to be respected, and the European administration does not particularly appreciate multipartite agreements in any one sector. Evolution is also expected in this area, in order to reconcile international competition rules with the will to build a global organization: waste decrease and local employment development for example. The final discussion point considers the SDSC approach's limits, areas of improvements and possible technological aids.

\subsection{New expected contractual tools}

The DSC is composed of several actors. In order to perpetuate the business connections among them, it is important to have contractual relations. The initial idea was to have a global contract signed by all the actors (Figure 3), but this is not acceptable for the lawyers. Due to the competition authority, the common rule is usually to have two-party contractors.

One solution that has been found is to have several parallel classical contracts (as described in Figure 4) at an upper level. These contracts are bound together by reference to a unique common model, and by engagement towards the other DSC actors.

Other contracts (as described in Figure 5) are necessary within the organization in order to guarantee the upper-level contracts. This two-level contractual organization does offer one solution, but new contractual tools have to be invented to ease this need of new types of contract. Incidentally, new business economy very often implies three actors: (1) a buyer; (2) a seller; and (3) a platform, in which case the two-party contracts are also not relevant.

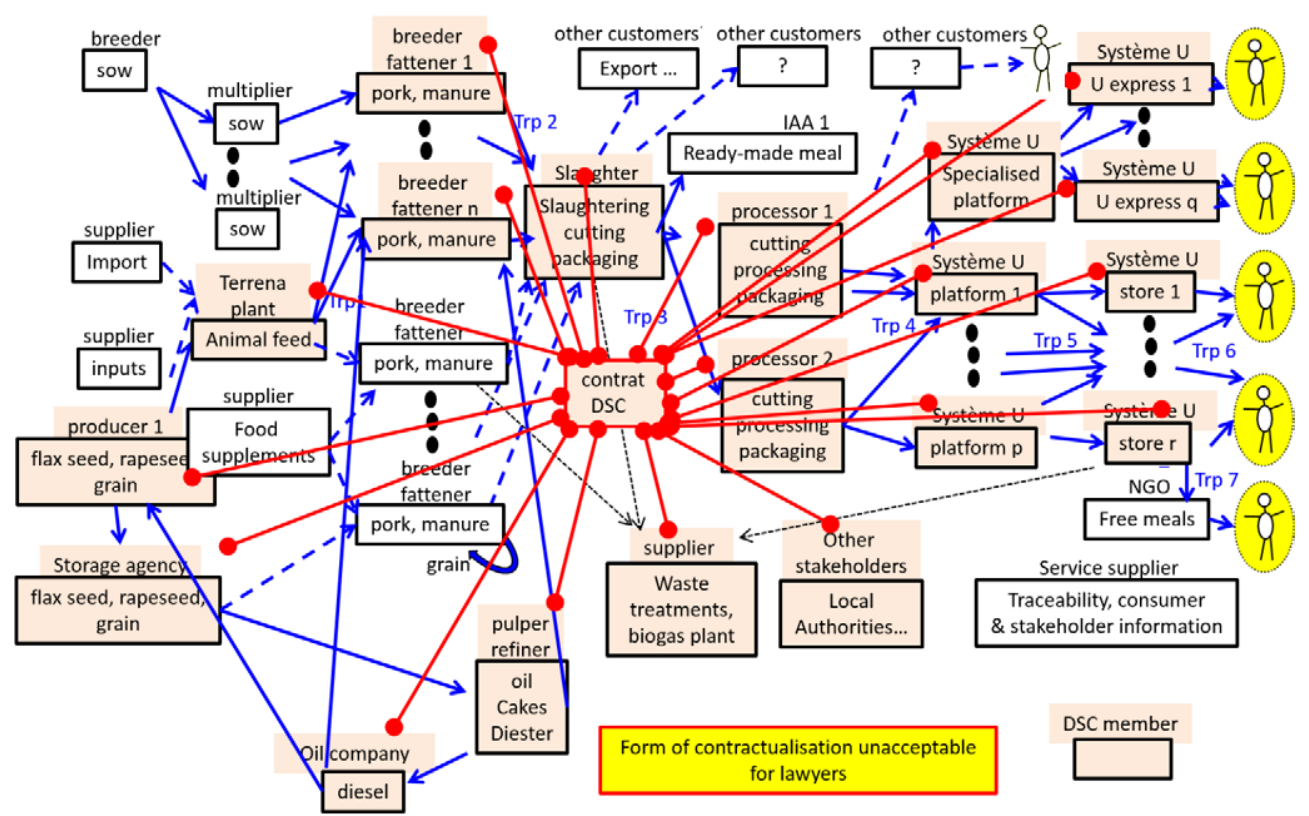

Figure 3. First idea of contractualization. 


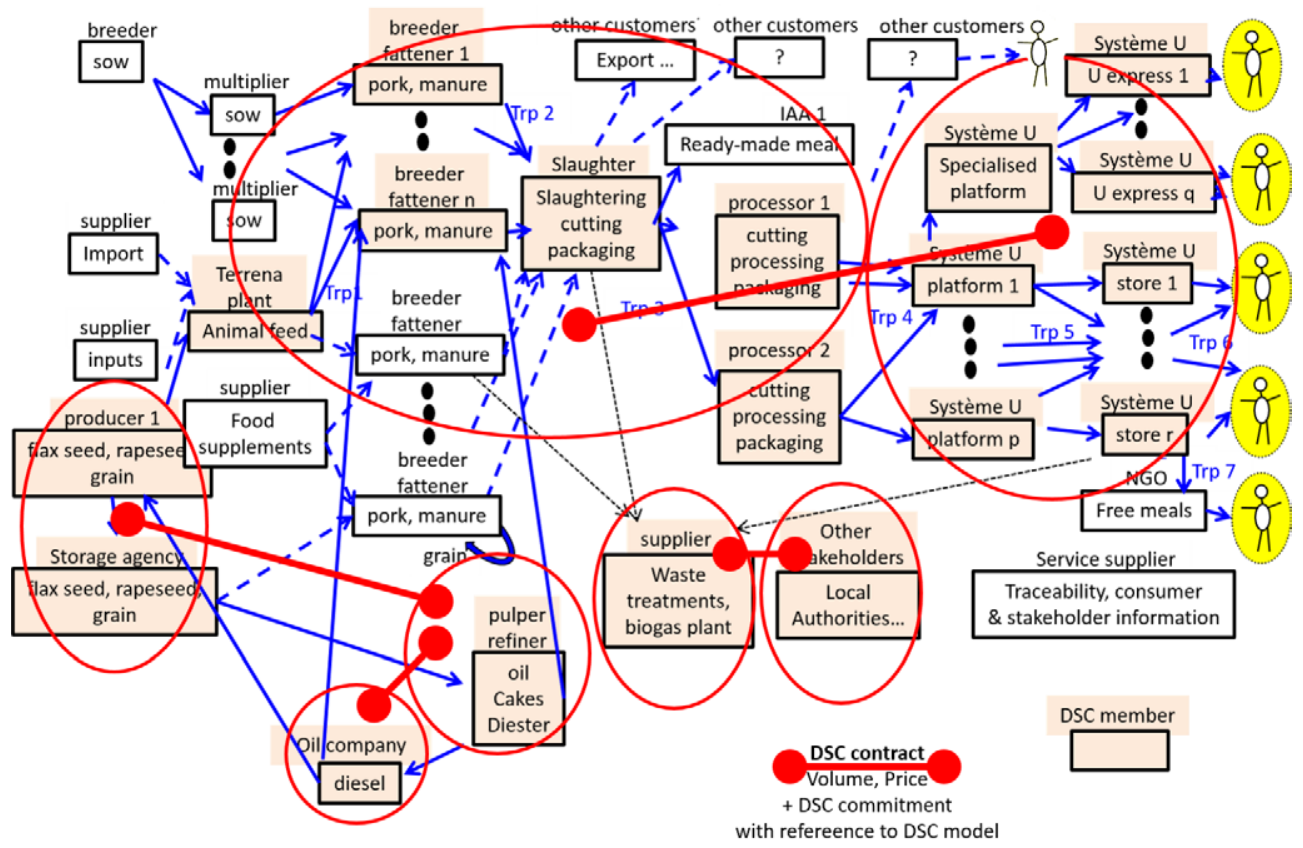

Figure 4. Alternative contracts at upper level.

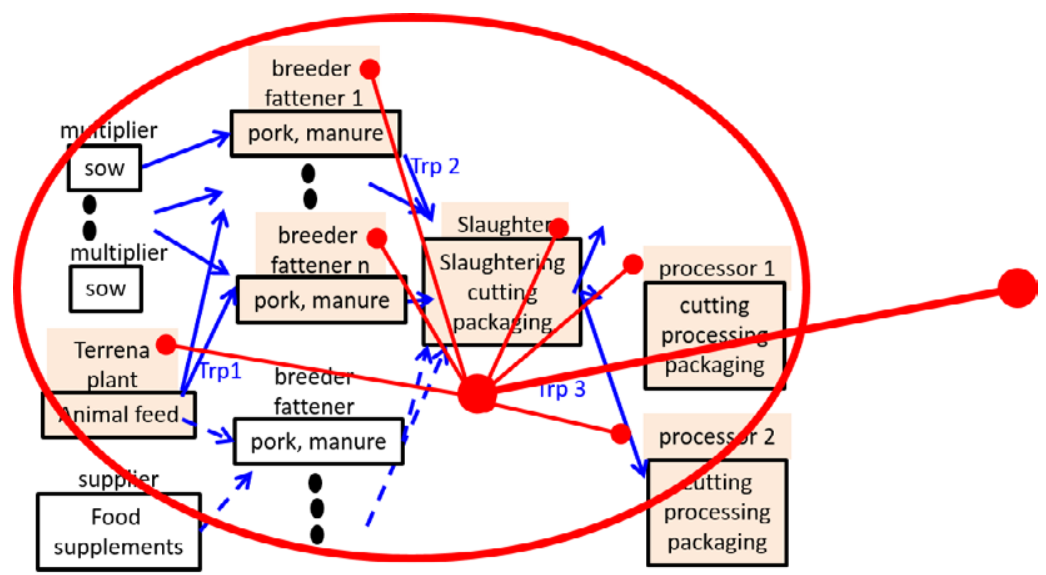

Figure 5. Example of contracts within an organization.

\section{- Contracts and governance}

In France, contractualization between agrifood actors participates in the new French agricultural policy via the Loi de Modernisation (Legifrance, 2010). This law seeks to promote contractual arrangements between all of stakeholders in order to reduce asymmetric information and to rebalance powers in favor of producers. Faced with distribution players, the law ${ }^{3}$ suggests contractual commitments in dairy, meat, fruit and vegetables. France opted for contractualization between producers and their buyers via the Loi de Modernisation. This contractualization policy aims at encouraging the different stakeholders to establish agreements to fix prices and quantities. The goal of these purchasing contracts is to smooth out price variations in order to avoid any excessive rise in costs between the different parties, including consumers, in the supply-chains (Filippi, 2015).

\footnotetext{
${ }^{3}$ See Arts. 221 and 222 of CMO.
} 
Unfortunately, French contractualization has failed to stabilize farmers' incomes. The main explanation is not only due to the difficulty of contracting between stakeholders for five years on price and volume, but also to the need to avoid conflicts with the competition authority. This is especially related to the fact that the contracts are signed between unorganized producers. The weaknesses of the collective organization, the producer organization, leads to a non-rebalance of power inside supply chains, together with an ensuing risk of failures related to the fall of price remuneration and farmer incomes (Haut and Raison, 2015). As explained by Royer and Gouin (2016), the institutional context suggests two types of enforcement, private and public: public enforcement, which is based on contract has to be reinforced by private enforcement, using the incitation of cooperative mechanisms (Hadfield, 2005). In this situation, SDSC offers various advantages in terms of sustainability, collective governance and mutual commitments. The governance of SDSC, combining both types of contract as agreement tools reflecting the common perspective.

\subsection{The SDSC approach: limits, areas of improvement and conditions}

The SDSC approach presents different kind of limits and areas of improvement:

- Respect of competition rules. World Trade Organization rules regarding free product circulation and free worker movement could raise problems when the organization of circular flows and guaranteeing local employment are to be envisaged. If the SDSC approach turns out to be very successful, the percentage of business made through DSC is going to grow and may reach a level that is too high for competition authorities. It should not be forgotten that public policy makers have to authorize the use of new contractual tools.

- SDSC approach applicability to all agrifood sectors. The approach seems to operate in the two sectors currently being tested (pork and vegetal oil) but must be validated in other sectors. In particular, the metamodel used to describe the sector must be consolidated. Big data modelization could also modify sector modelization.

- DSC tools development and operators. These tools could be expensive to develop. Is the cost affordable for one or several DSC members, or must the development and operation be mutualized by a third party? Data ownership and data valorization may then become a big issue.

The SDSC approach is also realistic with possible technological aids. One might ask the question: is the implementation of the SDSC approach realistic? The answer is yes if the stakeholders have a real desire to create additional value through better collaboration. This collaboration can be helped by new tools based on blockchain (Luo et al., 2018). The blockchain can first of all strengthen trust between the actors (Saberi et al., 2019). It can allow everyone to remain in control of their data. Each actor remains the owner of his data and filters the data he wants to transmit. It can also transmit more confidential data to a third party who can help manage the optimizations of the global collaboration. The blockchain facilitates the sharing of information between actors because this is the first important problem to solve when you want to set up a collaboration (Zeng et al., 2017). This has been verified in the experiments that have been carried out. The setting up of a blockchain has allowed the information sharing which has allowed to generate value. The blockchain is the guarantee for the actors but also for the final consumer that the data have not been modified and that they are therefore binding on their authors (which guarantees the quality of the data and also makes it easier to settle any subsequent disputes). This also limits the risks of collusion between actors.

\section{Conclusions and future perspectives}

Sustainability is associated with the idea that independent units, i.e. farmers and firms, work together in order to create added value and to share it. The goal is to avoid conflicts or create common/collective goals. The competitiveness of SDSC is that this collective organization contributes to creating better and sustainable added value for all members, including customers. So far, the SDSC approach has been tested in only two sectors. The experiment must be enlarged to other sectors. Further experimentation, a broader SDSC approach must be tested. For example, a DSC composed of two sector actors: the animal and agricultural sector. Agriculture gives seeds to make the oil and meal that can be part of animal feed, the manure is used 
in agriculture and we can think about more circular economy with diester production from oil, which is incorporated in fuel engines used in the fields. The experiment must also be tested on other sectors in order to validate its benefits. The associated tools must also become generic as far as possible. It is interesting to note that the blockchain is a tool that can help in the implementation of the SDSC approach. In addition, 'SDSC generic tools' are emerging. Indeed, a blockchain solution provider is currently developing specific SDSC add-on modules to facilitate the implementation of this approach for its customers. However the question of who, in future, will manage these tools (and associated data) is also a very important one. Big data must be used in future SDSC models. It is obviously a good idea for discovering new levers for value creation and making tools more accurate. But models must not become a black box. There is the temptation to have an increasingly sophisticated model in order to have more accurate tools to manage demand and supply but - if they become too complex - the actors will not be able to understand and validate them. Over sophistication could allow a loss of confidence to creep in, ultimately thwarting successful coordination between actors.

\section{Acknowledgements}

Funds from SDSC Chair, AgroParisTech, University of Paris Saclay.

\section{References}

Alchian, A.A. and H. Demsetz. 1972. Production, information costs, and economic organization. The American Economic Review 62(5): 777-795.

Berger, Y., Y. Marchal, Y. Riou and F. Champanhet. 2015. Mise en ouvre de la contractualisation dans la filière laitière française. Enjeux de la filière lait de vache dans le contexte de la fin des quotas. Conseil Général de l'Alimentation, de l'Agriculture et des Espaces Ruraux, No. 15053. Available at: https://agriculture.gouv.fr/sites/minagri/files/cgaaer_15053_2015_rapport-2.pdf

Chassagnon, V. 2011. The law and economics of the modern firm: a new governance structure of power relationships. Revue d'Economie Industrielle 134: 25-50.

Coase, R.H. 1937. The nature of the firm. Economica 4(16): 386-405.

Cox, A., J. Sanderson and G. Watson. 2001. Supply chains and power regimes: toward an analytic framework for managing extended networks of buyer and supplier relationships. Journal of Supply Chain Management 37(1): 28-35.

Elzen, B., F.W. Geels and K. Green (eds.) 2004. System innovation and the transition to sustainability: theory, evidence and policy. Edward Elgar Publishing, Cheltenham, UK.

Fama, E.F. 1980. Agency problems and the theory of the firm. Journal of Political Economy 88(2): 288-307.

Filippi, M. 2015. Faced with price volatility. The French contractualisation. Law and agricultural cooperatives. In: Novkovic, S. (ed.) Review of international co-operation. International Co-operative Alliance, Brussels, Belgium, pp. 89-102.

Gereffi, G., J. Humphrey and T. Sturgeaon. 2005. The governance of global value chains. Review of International Political Economy 12(1): 78-104.

Gold, S. and M.C. Schleper. 2017. A pathway towards true sustainability: a recognition foundation of sustainable supply chain management. European Management Journal 35(4): 425-429.

Grossman, S.J. and O.D. Hart. 1986. The costs and benefits of ownership: a theory of vertical and lateral integration. Journal of Political Economy 94(4): 691-719.

Hadfield, G.K. 2005. The many legal institutions that support contractual commitment. In: C. Ménard and M. Shirley (eds.) Handbook of new institutional economics. Springer, New York, NY, USA, pp. 787-915.

Hart, O. and J. Moore. 1990. Property rights and the nature of the firm. Journal of Political Economy 98(6): 1119-1158.

Hart, S.L. 1995. A natural-resource-based view of the firm. The Academy of Management Review 20(4): 986-1014.

Haut, C. and M. Raison. 2015. La situation du secteur laitier après les quotas. Rapport au Sénat No. 556, 25 juin, Paris, France, 101 pp. 
Ireland, R.D. and J.W. Webb. 2007. A multi-theoretic perspective on trust and power in strategic supply chains. Journal of Operations Management 25(2): 482-497.

Jensen, M.C. and W.H. Meckling. 1976. Theory of the firm: managerial behavior, agency costs and ownership structure. Journal of Financial Economics 3(4): 305-360.

Ketchen Jr, D.J. and G.T.M. Hult. 2007. Bridging organization theory and supply chain management: the case of best value supply chains. Journal of Operations Management 25: 573-580.

Kusi-Sarpong, S., H. Gupta and J. Sarkis. 2019. A supply chain sustainability innovation framework and evaluation methodology. Journal of Supply Chain Management 37(1) 1990-2008.

Lazzarini, S.G., F.R. Chaddad and M.L. Cook. 2001. Integrating supply chain and network analysis: the study of netchains. Journal of Chain and Network Science 1(1): 7-22. https://doi.org/10.3920/ JCNS2001.x002

Legifrance. 2010. No. 2010-874 du 27 juillet 2010 de modernisation de l'agriculture et de la pêche. Available at: https://tinyurl.com/vcjyn31

Luo, J., C. Qiu and F. Jia. 2018. Agri-food supply chain management: bibliometric and content analyses. Sustainability 10(1573): 1-22.

Marsden, T., J. Banks and G. Bristow. 2000. Food supply chain approaches: exploring their role in rural development. Sociologia Ruralis 40(4): 424-438.

Nasuelli, P., F. Clemente, R. Baggio, R. Berruto and P. Busato. 2015. Supply chains of products of animal origin: a complex network model for strategic management, International Journal on Food System Dynamics 6(4): 248-258.

Nieuwenhuis, P., A. Touboulic and L. Matthews. 2019. Is sustainable supply chain management sustainable? In: N. Yakovleva, R. Frei and S.R. Murthy. (eds.) Sustainable development goals and sustainable supply chains in the post-global economy. Springer, Cham, Switzerland, pp. 13-30.

Rastoin, J.L. and G. Ghersi. 2010. Le système alimentaire mondial, concept et méthodes, analyses et dynamiques. Editions Quae, Synthèses, Paris, France.

Reimann, F. and D.J. Ketchen. 2017. Power in supply chain management, Journal of Supply Chain Management 53(2): 3-9.

Rezaee, S.A., M. Oey, C. Nevejan and F. Brazier. 2015. Participatory demand-supply systems. Procedia Computer Science 44: 105-114.

Royer, A. and D.-M. Gouin. 2016. Pour une politique de contractualisation efficace et équilibrée: le rôle de l'encadrement institutionnel. Colloque SFER La libéralisation des marchés laitiers. June 9-10, 2016. Clermont-Ferrand, France, 22 pp.

Saberi, S., M. Kouhizadeh, J. Sarkis and L. Shen. 2019. Blockchain technology and its relationships to sustainable supply chain management. International Journal of Production Reserch 57(7): 2117-2135.

Surana, A., S. Kumara, M. Greaves and U.N. Raghavan. 2005. Supply chain networks: a complex adaptive systems perspective, International Journal of Production Research 43(20): 4235-4265. https://doi. org/10.1080/00207540500142274

Wieczorek, A.J. and M.P. Hekkert. 2012. Systemic instruments for systemic innovation problems: a framework for policy makers and innovation scholars. Science and Public Policy 39: 74-87.

Williamson, O.E. 1975. Markets and hierarchies: analysis and antitrust implications. Free Press, New York, NY, USA.

Williamson, O.E. 1985. The economic institutions of capitalism. Free Press, New York, NY, USA.

Zeng, Y., F. Jia, L. Wan and H. Guo. 2017. E-commerce in agri-food sector: a systematic literature review. International Food and Agri-business Management Review 20(4): 439-459. 
